\title{
Reviewing the trends of nursing doctoral thesis research in Hong Kong
}

\author{
Yingchun Zeng ${ }^{1 *}$, Samantha Pang ${ }^{2}$ \\ ${ }^{1}$ Department of Health and Physical Education, The Hong Kong Institute of Education, Hong Kong, China \\ ${ }^{2}$ School of Nursing, The Hong Kong Polytechnic University, Hong Kong, China \\ Email: ${ }^{*}$ chloezengyc@hotmail.co.uk
}

Received 14 August 2012; revised 18 September 2012; accepted 28 October 2012

\begin{abstract}
This review aimed to analyze the trends and contributions of nursing doctoral theses produced in Hong Kong. A total of 56 nursing doctoral theses were included in this review. The most often studied topic was cardiovascular rehabilitation care $(n=9,16 \%)$. More recently, the most often studied topics has been health technology advancements in nursing care $(n=$ $6,10.7 \%$ ). The common trend of study methods was to be quantitative in nature. Of the total, 35 out of 56 were quantitative studies. Half were experimental/ quasi-experimental research studies $(n=28,50 \%)$. For theoretical foundations or applications, the majority $(n=21,36 \%)$ of doctoral theses had no specific theoretical/conceptual models as study frameworks. This trend indicates that there is space for improving the theoretical and philosophical foundation of nursing research in Hong Kong. For the contributions of doctoral thesis research, Hong Kong nursing scholars place more emphasis on direct enhancement of clinical practice or the improvement of patient outcomes. This review provides concrete evidence of the status of nursing research and knowledge development in Hong Kong nursing.
\end{abstract}

Keywords: Nursing; Doctoral Education; Doctoral Thesis; Hong Kong

\section{INTRODUCTION}

Doctoral education for preparing nursing scholars commenced in Hong Kong (HK) around 1995. Doctoral nursing programs in HK incorporate the strengths of both the British model of mentored research training and the US model of formal course offering. With the global trend of technological advances and interdisciplinary care, the $\mathrm{PhD}$ nursing program alone could not meet the challenges of preparing nurses as researchers, teachers,

\footnotetext{
${ }^{*}$ Corresponding author.
}

and leaders for the dynamic healthcare environment [1]. In recent years, three universities have run taught doctoral programs specific to the professional practice of nursing: the Hong Kong Polytechnic University (PolyU) School of Nursing has provided a Doctor of Health Science (DHSc) program since 2004; the Chinese University of Hong Kong (CUHK) Nethersole School of Nursing has provided a Doctor of Nursing (DN) program since 2009; and the University of Hong Kong (HKU) School of Nursing has offered a DN program since 2010.

The defining feature of doctoral study is that nurse leaders are nurtured to generate and extend nursing knowledge and to use their expertise to lead the development of the nursing discipline [2,3]. The doctoral thesis is the capstone event of doctoral study. While developing their theses, doctoral students discover the cutting edge of the discipline [4]. Reviewing nursing doctoral theses could identify changing trends in the nursing profession as an academic discipline. Of the few published reviews of nursing doctoral research that have studied nursing dissertations/theses [5-8], none was conducted in HK. With a growing body of nursing doctoral theses in $\mathrm{HK}$, the aim of this review was to analyze the trends and contributions of these existing nursing doctoral theses.

\section{METHODS}

Three key word combinations were used to conduct the search: Nursing, doctoral theses and PolyU or CUHK or HKU among the Dissertations \& Theses Collection at Hong Kong Polytechnic University, the Dissertations and Theses Collection Consortium and the ProQuest Dissertations and Theses. The inclusion criteria included nursing-focused doctoral dissertation studies, conducted in three universities in Hong Kong, written in English or Chinese, for the academic degree of PhD or DHSc, and completed between 1996 and 2010 (at the time of searching, there were no completed DN dissertations). The exclusion criteria included those theses were not with a focus on nursing. As one nursing school before 2002 was named as Department of Nursing and Health 
Sciences, which included other health-related disciplines/ majors. The theses were read and studied, classified by topic, methods of investigation and theoretical foundation or application, and analyzed using descriptive statistics.

\section{RESULTS}

A total of 56 doctoral theses were included. Three theses were from the DHSc program, which is mainly focusing on training professional practitioners for playing the leadership role in clinical healthcare settings. The others were from the $\mathrm{PhD}$ program, which is mainly with a research focus on training researchers and educators for research centers or educational institutes. The number of theses produced in Hong Kong per year from 1996 to 2010 is shown in Figure 1. Since 2000, there have been an increasing number of theses produced per year. In 2003, there was only one graduate from a $\mathrm{PhD}$ program. Possibly due to the outbreak of SARS in China, public gathering activities, including oral defense of doctoral theses, may not have been encouraged in that year.

The distribution of these nursing doctoral theses was classified by general study topics and the life span. The classification of general study topics can be seen in Table 1. According to clinical specialty, cardiovascular care/rehabilitation ( $\mathrm{n}=9,16 \%$ ) were the most oftenstudied topics, followed by gerontology $(\mathrm{n}=8,14.2 \%)$, cancer care $(\mathrm{n}=6,10.7 \%)$, and maternity care $(\mathrm{n}=5$, $8.9 \%)$. With an increasing trend toward interdisciplinary care, digital health/health technology advancement has become one of the most frequently-studied topics in nursing doctoral research in HK. Six theses investigated the feasibility and reliability of non-invasive methods in screening hypertension or blood glucose measurement. In terms of the life span, the majority of theses focused
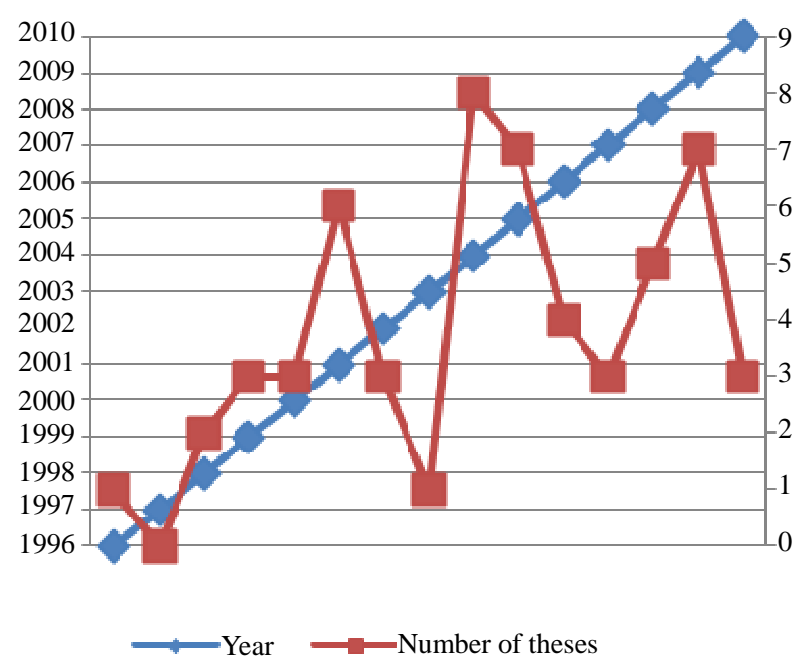

Figure 1. The number of nursing doctoral theses in Hong Kong from 1996-2010.
Table 1. Nursing doctoral theses by general topical categories $(\mathrm{N}=56)$.

\begin{tabular}{llc}
\hline Topic & $\mathbf{n}$ & \% \\
\hline Cardiovascular rehabilitation care & 9 & 16.0 \\
Gerontology & 8 & 14.2 \\
Cancer care & 6 & 10.7 \\
Digital health/health technology advancement & 6 & 10.7 \\
Maternity care & 5 & 8.9 \\
Public health/health behaviors & 5 & 8.9 \\
Childhood and family health & 4 & 7.2 \\
Palliative care & 2 & 3.6 \\
Pain management & 2 & 3.6 \\
Professional practice/development & 2 & 3.6 \\
Nursing education & 2 & 3.6 \\
Mental health & 1 & 1.8 \\
Nursing ethics & 1 & 1.8 \\
Healthcare system issues & 1 & 1.8 \\
Instrument development and validation & 1 & 1.8 \\
Theory model testing & 1.8 \\
\hline
\end{tabular}

on adult health ( $\mathrm{n}=42,75 \%$ ), followed by elderly care ( $\mathrm{n}=8,14.3 \%)$, child health $(\mathrm{n}=4,7.1 \%)$, and end-oflife care $(\mathrm{n}=2,3.6 \%)$.

Table 2 provides a descriptive summary of all doctoral thesis studies by the method of investigation. Of the total, it appears that 35 out of 56 were quantitative studies that were developed from classical models such as descriptive ( $\mathrm{n}=2,3.6 \%$ ), exploratory ( $\mathrm{n}=5,8.9 \%$ ), and experimental/quasi-experimental research $(n=28,50 \%)$. These data reflect the growing trend of experimental studies that have become a major approach in doctoral research in HK. The qualitative studies, in turn, totaled 12 and were developed from methods such as phenomenology $(n=6)$, grounded theory $(n=3)$, ethnographic studies $(n=2)$, action research $(n=1)$ and case study $(n=$ $1)$. These qualitative studies mark the changing paradigms in search of the entire phenomenon and much the broader approach to reality. Eight doctoral studies that combined qualitative and quantitative methods, without showing a trend, do however demonstrate clarity of purpose for the domain of triangulation for broader and deeper knowledge on the object of study.

For the distribution of 56 doctoral theses' theoretical foundations and/or applications, nine doctoral theses generated specific theoretical or conceptual models in their own studied areas. Thirteen doctoral studies directly tested existing theories or applied some conceptual models as study frameworks. Twenty-one doctoral theses failed to describe definite theoretical or conceptual models as study frameworks. Therefore, it was revealed a trend towards space for improving the theoretical and 
Table 2. Nursing doctoral theses by research design $(\mathrm{N}=56)$.

\begin{tabular}{|c|c|c|}
\hline Study designs & $\mathbf{n}$ & $\%$ \\
\hline Quantitative studies & 35 & 62.5 \\
\hline Descriptive & 2 & 3.6 \\
\hline Exploratory & 5 & 8.9 \\
\hline Quasi-experimental/experimental & 28 & 50.0 \\
\hline Qualitative studies & 13 & 23.2 \\
\hline Phenomenology & 6 & 10.7 \\
\hline Grounded theory & 3 & 5.3 \\
\hline Ethnographic & 2 & 3.6 \\
\hline Action research & 1 & 1.8 \\
\hline Case study & 1 & 1.8 \\
\hline Mixed methods & 8 & 14.3 \\
\hline QUAL + quan* & 2 & 3.6 \\
\hline QUAN + qual* & 6 & 10.7 \\
\hline
\end{tabular}

"Abbreviation: QUAL + quan: Qualitative core component of the project with a simultaneous quantitative supplementary component; QUAN + qual: Quantitative core component of the project with a simultaneous qualitative supplementary component [9].

philosophical foundation of nursing research in HK.

\section{DISCUSSION}

The growing body of nursing knowledge is significantly enhanced by doctoral level research. Some theses [10-14] emphasized psychosocial aspects of nursing care that are congruent with holistic practice and concern for the mind-body connection. One doctoral thesis [15] was important in documenting the evolution of the nursing profession in China, and bears out the uniqueness of nurses' contribution to healthcare ethics.

Two thesis studies [16,17] examined nursing education issues. More studies related to investigating nursing education issues are encouraged, considering the growing international crisis that relates to nurse workforce shortages, and the aging of the nursing workforce [18]. In addition, more studies need to investigate healthcare system issues due to the ever-transforming healthcare and delivery systems in HK. The present review revealed only one thesis [19] on the healthcare environment and reforms impacting the role of nurses. This was in contrast to Hooker and Mayo's [5] review of all doctoral dissertations, where they reported that $75 \%$ of the nurse practitioner-focused doctoral studies explored topics relevant to socioeconomic issues. Possible explanations for these differences are that HK nursing scholars place more emphasis on clinical practice and value nursing scholarship more for its direct contributions to the improvement of clinical nursing practice and related patient outcomes.

Many of the studies examined clinical nursing care such as cardiovascular, gerontology and cancer care, which indicate the strength of nurses' contribution to patients' health outcomes and practice advancement. The overview trend of these doctoral theses was that cardiovascular rehabilitation care was the most often-studied topic, meeting the priority health needs faced by the HK population. According to the HK Department of Health's Thematic Household Survey Report [20], disease of the heart or circulatory system is the most commonly cited disease requiring long-term follow-up care.

The more recent trend among these doctoral studies was for the predominant approach to be related to the construction of a technical basis for care in HK. In the past two years, five theses [21-25] have focused on examining technological advancements in nursing care. For example, Lam [22] conducted a clinical evaluation of non-invasive blood glucose measurement. Ng [23] applied and evaluated the effectiveness of a non-invasive method to manage the symptoms of obstructive sleep apnea. Advances in scientific and technological development in the area of nursing and health require a research environment that opens new possibilities for the construction of scientific standards compatible with the needs of academic excellence [26]. The dynamic healthcare environment places more value on technological advancement and interdisciplinary care. Therefore, nurses should broaden the traditionally defined professional boundaries and be prepared to meet these challenges.

Based on the finding of the present review, the predominant trend of study designs is toward the quasi-experimental/experimental. Fifty percentages of doctoral theses in the present review used quantitative experimental studies, possibly due to the current emphasis on evidence-based nursing practice predicated on a hierarchy of evidence that esteems experimental research above evidence gathered via other approaches [27]. Although experimental research studies such as randomized controlled trials are important, experimental approaches are rarely well suited for the study of nursing practice and related multidimensional components of care [7]. An overemphasis on experimental research at the expense of more qualitative approaches may be questionable, as qualitative studies could explore the nursing phenomenon from a much broader perspective.

Although the key mission of nursing doctoral education is to educate future scholars regarding building up nursing's own theoretical foundations and their implications for continued knowledge development, some doctoral theses $(n=21,36 \%)$ have no specific theoretical/ conceptual models as study frameworks. Among these 21 doctoral theses, some were qualitative studies. Pilot and Beck [28] suggest that the frameworks of qualitative studies are part of the research tradition in which the study is embedded: ethnographers usually begin their 
work within a theory of culture. Grounded theory research incorporates sociological principles into its framework and its approach to looking at phenomena [28]. However, ten experimental intervention studies failed to articulate a specific study framework or provide an explicit theoretical or conceptual model. A theoretical/conceptual framework is the conceptual underpinning of a study [28]. The purpose of formulating a conceptual framework is to provide a conceptual perspective about the interrelated phenomena under investigation. Without a sound theoretical basis, the effectiveness of a patient intervention is in doubt [29]. Therefore, theory-based intervention studies should be required for future nursing doctoral research in HK.

The total number of theses may be regarded as a limitation, because some nurses may obtain their PhDs in other subjects and departments; in particular, many HK nurses and nurse academics seek their doctoral studies in the US/UK or Australia. Reviewing nursing doctoral theses produced in HK is not amenable to wide generalization. Nevertheless, this descriptive review offers an important source of information in the area of doctoral level research in nursing, and may serve to guide future doctoral research study and nursing knowledge development in $\mathrm{HK}$.

\section{CONCONLUSION AND IMPLICATIONS}

The analysis of scientific production originating from the 56 theses studied indicates concrete evidence of the status of nursing research and knowledge development in $\mathrm{HK}$ nursing. In general, the doctoral theses covered the lifespan and a variety of topics and specialty areas of practice. However, few studies explored the issues of end of life, mental health, ethics, or the healthcare system. Future doctoral research should pay thoughtful consideration to these under-studied areas. While these doctoral studies adopted a range of research methods, half of them were quantitative experimental research. As qualitative studies can explore nursing phenomena from a broader perspective, incorporating both qualitative and quantitative approaches in future nursing doctoral studies is worthy of attention. Based on the findings of the current review, few experimental intervention studies had a theoretical/conceptual framework. To ensure the scientific standards of nursing interventions, theory-based intervention studies should be required for future nursing doctoral research in $\mathrm{HK}$.

\section{REFERENCES}

[1] Ketefian, S., Davidson, P., Daly, J., Chang, E. and Srisuphan, W. (2005) Issues and challenges in international doctoral education in nursing. Nursing and Health Sciences, 7, 150-156.

doi:10.1111/j.1442-2018.2005.00240.x

[2] Burton, C.R., Duxbury, J., French, B., Monks, R. and Carter, B. (2009) Re-visioning the doctoral research degree in nursing in the United Kingdom. Nurse Education Today, 29, 423-431. doi:10.1016/j.nedt.2008.10.002

[3] Ketefian, S. (2008) Doctoral education in the context of international development strategies. International Journal of Nursing Studies, 45, 1401-1402. doi:10.1016/j.ijnurstu.2008.02.002

[4] Robinson, S. and Dracup, K. (2008) Innovative options for the doctoral dissertation in nursing. Nursing Outlook, 5, 174-178.

[5] Hooker, R.S. and Mayo, H.G. (2002). Doctoral dissertations on nurse practitioners: 1970-2000. Journal of the American Academy of Nurse Practitioners, 14, 276-284. doi:10.1111/j.1745-7599.2002.tb00125.X

[6] Lundgren, S.M., Valmari, G. and Skott, C. (2009) The nature of nursing research: Dissertations in the Nordic countries, 2003. Scandinavian Journal of Caring Sciences, 23, 402-416. doi:10.1111/j.1471-6712.2008.00631.x

[7] Spear, H.J. (2007) Nursing theory and knowledge development: A descriptive review of doctoral dissertations, 2000-2004. Advances in Nursing Science, 30, E1-E14.

[8] Shin, H., Sung, K., Jeong, S.H. and Kim, D. (2008) Trends of doctoral dissertations in nursing science: Focused on studies submitted since 2000. Journal of Korean Academy of Nursing, 38, 74-82. doi:10.4040/jkan.2008.38.1.74

[9] Morse, J. and Niehaus, L. (2007) Combining qualitative and quantitative methods for mixed methods design. In: Munhall, P., Ed., Nursing Research: A Qualitative Perspective, 4th Edition, Jones and Bartlett, Sudbury, 541-554.

[10] Chang, A.M. (1999) Psychosocial nursing intervention to promote self-esteem and functional independence following stroke. Ph.D. Thesis, The Chinese University of Hong Kong, Hong Kong.

[11] Sit, W.H. (2000) The impact of social support on perceived well-being of stroke survivors. Ph.D. Thesis, The Hong Kong Polytechnic University, Hong Kong.

[12] Chow, L.W. (2001) Psychosocial dimensions in caring: The lived experience of parents after the birth of children with cleft lip and/or palate. Ph.D. Thesis, The Hong Kong Polytechnic University, Hong Kong.

[13] Ip, W.Y. (2005) The effect of a theory-based intervention on promoting self-efficacy for childbirth among pregnant women in Hong Kong. Ph.D. Thesis, The Chinese University of Hong Kong, Hong Kong.

[14] Hui, C.W. (2008) The transition to motherhood for Chinese women. Ph.D. Thesis, The University of Hong Kong, Hong Kong.

[15] Pang, M.C. (1999) From virtue to value: nursing ethics in modern China. Ph.D. Thesis, The University of Hong Kong, Hong Kong.

[16] Wong, W.L. (2001) Conceptual understandings and their application to a problem assessment task: Implications for 
nursing curriculum design. Ph.D. Thesis, The Hong Kong Polytechnic University, Hong Kong.

[17] Xia, H.O. (2007) Establishing an innovative teaching model for a student exchange programme in nursing education. Ph.D. Thesis, The Hong Kong Polytechnic University, Hong Kong.

[18] Redman, R.W. (2007) Critical challenges in doctoral education: Highlights of the biennial meeting of the international network for doctoral education in nursing, Tokyo, Japan, 2007. Japan Journal of Nursing Science, 4, 61-65. doi:10.1111/j.1742-7924.2007.00081.X

[19] Wong, F.K.Y. (1996) Health care reform and the transformation of nursing in Hong Kong. Ph.D. Thesis, The Chinese University of Hong Kong, Hong Kong.

[20] Hong Kong Department of Health (2005) Thematic household survey report No. 30, Census and Statistics Department. Persons who had diseases that required long-term follow-up by doctors by type of disease, 2005. http://www.dh.gov.hk/english/pub_rec/pub_rec_ar/pub_r ec_ncd.html

[21] Chen, J.H. (2009) Visualization and classification of the heart sounds of patients with pulmonary hypertension. Ph.D. Thesis, The Hong Kong Polytechnic University, Hong Kong.

[22] Lam, C.H. (2009) Clinical evaluation of non-invasive blood glucose measurement by using near infrared spectroscopy via inter-and intra-subject analysis. Ph.D. Thesis, The Hong Kong Polytechnic University, Hong Kong.

[23] Ng, S.L. (2009) Instantaneous effect of meridian point stimulation for managing sleep apnoea. Ph.D. Thesis, The Hong Kong Polytechnic University, Hong Kong.

[24] Wong, M.C. (2010) The feasibility of contact heat evoked potentials (CHEPs) in early detection of symptomatic diabetic distal symmetric polyneuropathy (DSP). Ph.D. Thesis, The Hong Kong Polytechnic University, Hong Kong.

[25] Tang, C.Y. (2010) Developing an objective traditional Chinese medicine pulse diagnostic model in essential hypertension. Ph.D. Thesis, The Hong Kong Polytechnic University, Hong Kong.

[26] Erdmann, A.L., Silva, I.A., Rodrigues, R.A., Fernandes, J.D., Vianna, L.A., Lopes, M.J., et al. (2005) Nursing doctoral theses produced on graduate programs between 1983-2001. Journal of School Nursing Da USP, 39, 497505.

[27] Fulbrook, P. (2003) Developing best practice in critical care nursing: Knowledge, evidence and practice. Nursing in Critical Care, 8, 96-102. doi:10.1046/j.1478-5153.2003.00010.x

[28] Polit, D.F. and Beck, C.T. (2012) Nursing research: Generating and assessing evidence for nursing practice. 9th Edition, Lippincott Williams \& Wilkins, Philadelphia, 126-149.

[29] Kok, G., van den Borne, B. and Mullen, P.D. (1997) Effectiveness of health education and health promotion: Metaanalyses of effect studies and determinants of effectiveness. Patient Education and Counseling, 30, 19-27. doi:10.1016/S0738-3991(96)00953-6 